\title{
INFLUENCE OF GRANULOMETRIC CEMENT CHARACTERISTICS ON THE UNIFORMITY DEGREE
}

\author{
Corina MITU - Lecturer, PhD, Technical University of Civil Engineering Bucharest, The Faculty of Building and \\ Services \\ Lidia RADU - Lecturer, PhD, Technical University of Civil Engineering Bucharest, The Faculty of Civil, Industrial \\ and Agricultural Buildings

\begin{abstract}
In industrial practice, the dimensional characterization of the polygranular materials can be done, experimentally and/or by calculation, on the basis of various types of granulometric distribution laws, of the different types of diameters, of the specific surface and of some indicators related to the granulometric uniformity. This paper aims at introducing a new indicator, called granulometric uniformity degree, defined on the basis of some informational statistics elements, and calculated in a unique way, different from any particular type of granulometric distribution. At the same time, a series of correlations between the granulometric uniformity degree and different characteristic diameters is pointed out, i.e. the specific surface of cements, characterized by the Rosin-Rammler-Sperling ganulometric distribution.
\end{abstract}

Keywords: polygranular material, characteristic diameters, specific surface

\section{Introduction}

In the cement industry, regardless of the field and the processing type (humid or dry), the raw materials, the clinker and cement, represent polygranular materials, which, according to the specific of the operation from the technology process in which they appear, have a certain dispertion of the diameters around a medium value, and different granulometric distributions, unimodal or multimodal.

The granulometric characterization of these polygranular materials is made, from one case to another, through granulometric analysis, based on classification operation, or on some granulometric distribution functions.

Usually, in the industrial practice, the quantitative characterization of a polygranular material in terms of granulometry is made through the residue values on one or possibly two sites and/or through the value of the specific surface. In some cases, the information quantity is sufficient, but, many a time, this simple mode of approaching cannot provide, qualitatively and quantitatively, the necessary information for an optimal processing of the raw materials. The negative repercussion can be seen in a number of technological operations (crushing-grinding, separation, dosing, classification, homogenization etc.), but also in the developing way of thermic transfer, clinkering and cement hydration processes.

For obtain good quality clinkers and cements are two important requirements which that these materials must meet: an advanced chemical homogeneity and certain granulometric distributions, respectively the granulometric uniformity.

In practice, depending on the particularities at which the polygranular material takes part, in various stages of the technological process to obtain Portland cement, and on the cement quality, expressed through its properties, the granulometric distribution must show a certain uniformity degree, that is in closely dependence with the distribution type (unimodal or multimodal) and with the dispersion degree of the values for the diameter of the different granulometric classes particles in comparison with the medium value. Size uniformity of the powder material is lower when the frequencies of occurrence of different particle size classes have closer values. Thus, the 
granulometric uniformity degree of polygranular materials can be different, even if their specific surface or the medium diameter is the same [1 - 3].

Different coefficients were proposed for the granulometric uniformity evaluation of the polygranular materials (some coefficients are included in the distribution type defining law, and others can be calculated starting from the concrete form of the distribution law), which measure the particles dispersion on the entire characteristic granulometric spectrum. These coefficients are used only in some particular cases; for example, when the distribution function which characterizes exactly the particles dispersion on all the granulometric spectrum is known [1 - 6].

Hence, it seems to be necessary to establish a generalized indicator to quantitatively evaluate the uniformity of the polygranular materials, based on the concept of order/disorder (uniformity/ununiformity), used no matter the dimensions and the repartition mode of the component granulometric classes..

In this paper, the authors show a series of correlations between the uniformity degree (UD) and different granulometric parameters: $\bar{x}$ - mean diameter, $\mu m, x_{50}$ - mesh size screen for passing $50 \%$ of material, $\mu m, x^{\prime}$ - specific diameter of the particles, $\mu m, n$ - uniformity index and $\mathrm{S}$ specific surface, $m^{2} / g$.

\section{Dimensional Characterization of Polygranulare Materials}

The granules repartition mode on various dimension classes represents one of the most important characteristics of polygranular materials. As a result, in time, based on the statistical analysis of a great number of experimental data or out of theoretical considerations (more rarely), more mathematical expressions representing distribution laws have been developed in literature $[1-3,7-10]$. A series of this kind of laws can be used to characterize the granulometric distribution of polygranular materials (raw materials, mixture of raw materials, cement), from the cement field (table 1).

Table 1

Distribution laws

\begin{tabular}{|c|l|c|}
\hline No. & \multicolumn{1}{|c|}{ Name distribution laws } & Mathematical expression \\
\hline 1 & Rosin-Rammler- Sperling law & $\left(\frac{x}{x_{\max }}\right)^{-\left(x / x^{\prime}\right)^{n}}$ \\
\hline 2 & Gaudin- Andreev- Schumann law & $\frac{a x^{a-1}}{x_{\text {max }}^{a}-x_{\text {min }}^{a}}, x \in R^{+}, a>0$ \\
\hline 3 & Dinger- Funk law & $\frac{1}{2 \lambda} e^{-\frac{|x-\mu|}{\lambda}}, x \in R^{+}, \lambda>0$ \\
\hline 4 & Laplace law & $\frac{1}{\sigma \cdot \sqrt{2 \pi}} e^{-\frac{(x-\bar{x})^{2}}{2 \sigma^{2}}, x \in R^{+}, \sigma>0}$ \\
\hline 6 & Exponential law & $\frac{1}{\lambda} e^{\frac{x}{\lambda}}, x \in R^{+}, \lambda>0$ \\
\hline
\end{tabular}

where: $x$ is particle diameter, $\mu m, x^{\prime}$ - position parameter or specific diameter of the particles indicating the fineness of the coarse dispersion, $\mu m, n$ and $m$ - uniformity indices, $x_{\min }$ - minimum diameter of the particles, $\mu m, x_{\max }$ - maximum diameter of the particles, $\mu m, a$ - index of 
dispersion, $\mu$ - geometric mean diameter, $\mu m, \lambda$ - offense geometry, $\bar{x}$ - mean diameter, $\mu m, \sigma$ standard deviation.

In the cement industry, the polygranular material characterization in terms of granulometry is the most frequent one, with the help of Rosin-Rammler-Sperling law (table 1, pos. 1) which has been verified on more experimental data. In this case, the following relations can be written for the polygranular material:

$$
\begin{aligned}
& \mathrm{T}(\mathrm{x})=1-\mathrm{R}(\mathrm{x})=1-e^{-\left(x / x^{\prime}\right)^{n}} \\
& \mathrm{f}(\mathrm{x})=\frac{d T(x)}{d x}=\frac{n}{x^{\prime}}\left(\frac{x}{x^{\prime}}\right)^{n-1} e^{-\left(x / x^{\prime}\right)^{n}}
\end{aligned}
$$

where $R(x)$ is the residue on sieve, $\%, T(x)$ - passing through the sieve, $\%, f(x)$ - distribution density, $x$ - particle diameter, $\mu m, x^{\prime}$ - position parameter, $\mu m, n$ - uniformity index, that measures the dispersion of the granulometric distribution.

Also, the dimensional characterization of the polygranular materials can be also done by calculating some characteristic diameters (table 2), and for a series of practical situations it is better to use the Blaine specific surface (table 2, pos. 6) [2, 3, 10 - 12].

Table 2

Relations for parameters may be used for characterizing the polygranular materials

\begin{tabular}{|c|l|c|}
\hline No. & \multicolumn{1}{|c|}{ Name of characteristics size } & Mathematical expression \\
\hline 1 & Mean diameter & $x_{\max } \int x \cdot f(x) d x$ \\
$x_{\min }$ \\
\hline 2 & $\mathrm{x}_{50}$ diameter & $\left(\mathrm{x}^{\prime}\right) \cdot(\ln 2)^{1 / \mathrm{n}}$ \\
\hline 3 & Geometry diameter & $\prod_{i=1}\left(x_{i} f_{i}\right.$ \\
\hline 4 & Harmonic diameter & $\sum_{i=1}^{N}\left(\frac{f_{i}}{x_{i}}\right)^{-1}$ \\
\hline 5 & x $_{80}$ Bond diameter & $\frac{6000000}{S_{s p} \cdot \sqrt{\rho^{5}}}$ \\
\hline 6 & Blaine specific surface & $\frac{\sqrt{\varepsilon^{3} \cdot t}}{\rho \cdot(1-\varepsilon) \sqrt{\eta}}$ \\
\hline
\end{tabular}

where: $x$ is particle diameter, $\mu m, x_{\min }, x_{\max }$ minimum diameter, maximum of particles respectively, $\mu m,(x)$ - distribution density, $x_{50}$ - mesh size screen for passing $50 \%$ of material, $\mu m, x^{\prime}$ - position parameter, $\mu m, n$ - uniformity index, $N$ - granulometric class number (events, structural units) of the system; $f_{i}$ - existential frequency for i state, $0 \leq f_{i} \leq 1, i=\overline{1, N} ; \sum_{\mathrm{i}=1}^{\mathrm{N}} \mathrm{f}_{\mathrm{i}}=1$, $\rho$ - particles density, $\mathrm{g} / \mathrm{cm}^{3}, K$ - constant device, $\mathrm{g} \cdot \mathrm{cm}^{-2} \cdot \mathrm{s}^{-2}, \varepsilon$ - porosity of the cement layer, $t$ - time passing of a constant volume of air through cement pill, $s, \eta$ - viscosity air to working temperature, $\mathrm{Ns} / \mathrm{m}^{2}$.

The granulometric distribution laws contain coefficients in the defining equation, on the basis of which the granulometric uniformity degree can be evaluated, but the analysis presented in article $[13,14]$ shows that these can characterize a blending only in certain particular cases.

In other situations, in order to appreciate the uniformity degree of the polygranular materials a series of classic indicators can be used: dispersion $\left(\sigma^{2}\right)$ is arithmetic mean of the squared deviations of individual values toward the arithmetic mean, coefficient of variation $(v)$ is a 
measure of relative dispersion which describes deviation as a percentage of the arithmetic mean and asymmetry appears when all the three values modal, median and average are different $[5,8]$.

For a polygranular material, the coefficients presented can define the granulometric uniformity degree of a polygranular material, only if the granulometric distribution is described by a single distribution function and if the distribution law describes exactly the particles dispersion on the entire characteristic granular spectrum; these conditions are not fulfilled in practice.

In this context, it was proposed that the uniformity degree of a polygranular material should be determined within the informational energy, $\left(E_{i}\right)$ (eq. 3) proposed by Onicescu [15].

$$
\mathrm{E}_{\mathrm{i}}=\sum_{i=1}^{N} f_{i}^{2}
$$

where: $\mathrm{f}_{\mathrm{i}}$ is existential frequency for i state, $0 \leq f_{i} \leq 1, i=\overline{1, N}, \sum_{i=1}^{N} f_{i}^{2}=1, N$ - the state number (events, structural units) of the system.

Considering the polygranular material as a system formed of $N$ granulometric fractions, where every granulometric fraction $(i)$ has the appearance frequency $\left(f_{i}\right)$ it can be appreciated that its granulometric uniformity degree is numerically equivalent to the informational energy proposed by Onicescu $\left(E_{i}\right)$. For a monogranular material, the uniformity degree is maximum, respectively 1 or $100 \%$, and for a completely disordered mix (non-uniform) $U D=O$.

Considering that the granulometric distributions for polygranular materials are described quantitatively by the Rosin-Rammler-Sperling law, the integral relation is chosen in order to determinate the granulometric uniformity degree (relation 4).

$$
\mathrm{UD}=\int_{x_{\min }}^{x_{\max }} f^{2}(x) d x
$$

where: $f(x)$ represents the allocation density for a continuous variable $x$ ( $x$ being the particle's diameter), $x_{\min }, x_{\max }$ - minimum, respectively maximum diameter of the particles, $\mu m$.

\section{Correlations Uniformity Degree - Granulometric Characteristics}

In this paper the results obtained on the basis of some numerical simulations which reveal the existence of dependencies between the granulometric uniformity degree and different granulometric characteristics $\left(\bar{x}\right.$ - mean diameter, $\mu m, x_{50}$ - mesh size screen for passing $50 \%$ of material, $\mu m, x^{\prime}$ - specific diameter of the particles, $\mu m, S$ - specific surface, $\mathrm{m}^{2} / g$ ) of Portland cements characterized by the Rosin-Rammler-Sperling distribution (fig. 1 - 9) are presented.

The correlations UD-granulometric characteristics are presented for various industrial Portalnd cements $[1,2,6,16]$ in figures $2,4,6,8$, considering $x_{\min }=1 \mu m$ and $x_{\max }$ having various values in the interval $80-200 \mu \mathrm{m}$, while in figures 3, 5, 7, 9 the correlations existing between the same statistical characteristics are presented, obtained however for six types of Portland cements [17], at which the density (p) and $x^{\prime}, n$ parameters of the Rosin-Rammler-Sperling distribution curves are known. For every Portland cement type three samples were considered, therefore 18 Portland cement types noted $\mathrm{C}_{1}-\mathrm{C}_{18}$ were analysed (table 3 ), and the results were compared to those obtained on different industrial Portland cements.

For each of the 18 Portland cements the following were calculated: granulometric uniformity degree (relation 4), mean diameter (table 2, position 1), $x_{50}$ diameter (table 2, position 2) and the specific surface, in $\mathrm{m}^{2} / g$ (relation 7), taking into account that the limit values of the particles diameter are $x_{\min }=1 \mu \mathrm{m}$ and $x_{\max }=100 \mu \mathrm{m}$. 
The granulometric characteristics and the densities of the analysed industrial cements

\begin{tabular}{|c|c|c|c|c|c|c|c|c|}
\hline No. & Cement & Density, $\mathrm{g} / \mathrm{cm}^{3}$ & $\mathrm{x}^{\prime}, \mu \mathrm{m}$ & $\mathrm{n}$ & Cement & Density, $\mathrm{g} / \mathrm{cm}^{3}$ & $\mathrm{x}^{\prime}, \mu \mathrm{m}$ & $\mathrm{n}$ \\
\hline 1 & $\mathrm{C}_{1}$ & 3.15 & 31.3 & 0.99 & $\mathrm{C}_{10}$ & 3.12 & 27.6 & 1.09 \\
\hline 2 & $\mathrm{C}_{2}$ & 3.10 & 24.8 & 0.90 & $\mathrm{C}_{11}$ & 3.05 & 22.7 & 0.94 \\
\hline 3 & $\mathrm{C}_{3}$ & 3.03 & 19.6 & 0.80 & $\mathrm{C}_{12}$ & 3.00 & 15.3 & 0.83 \\
\hline 4 & $\mathrm{C}_{4}$ & 3.18 & 21.0 & 1.11 & $\mathrm{C}_{13}$ & 3.04 & 26.5 & 1.12 \\
\hline 5 & $\mathrm{C}_{5}$ & 3.10 & 16.0 & 0.99 & $\mathrm{C}_{14}$ & 2.98 & 18.8 & 0.98 \\
\hline 6 & $\mathrm{C}_{6}$ & 3.03 & 11.3 & 0.84 & $\mathrm{C}_{15}$ & 2.92 & 14.5 & 0.85 \\
\hline 7 & $\mathrm{C}_{7}$ & 3.15 & 13.0 & 1.14 & $\mathrm{C}_{16}$ & 3.04 & 19.7 & 1.12 \\
\hline 8 & $\mathrm{C}_{8}$ & 3.10 & 10,8 & 1.02 & $\mathrm{C}_{17}$ & $3, .01$ & 16.5 & 0.99 \\
\hline 9 & $\mathrm{C}_{9}$ & 3.05 & 8.6 & 0.92 & $\mathrm{C}_{18}$ & 2.96 & 15.0 & 0.82 \\
\hline
\end{tabular}

$$
\mathrm{S}=\frac{6}{\rho \cdot x^{\prime}} \int_{x_{\min }}^{x_{\max }} \cdot \frac{f(x)}{x^{-1}} d x
$$

where: $f(x)$ represents the distribution density for a continuous variable $x$ ( $x$ being the particle diameter), $\rho$ - cement density, $\mathrm{g} / \mathrm{cm}^{3}, x^{\prime}$ - granules characteristic diameter, $\mu m$.

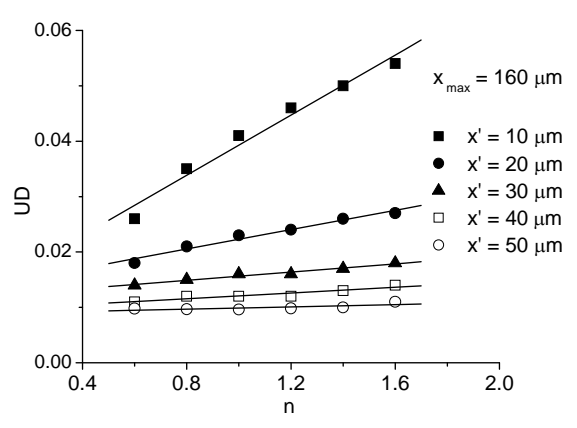

(a)

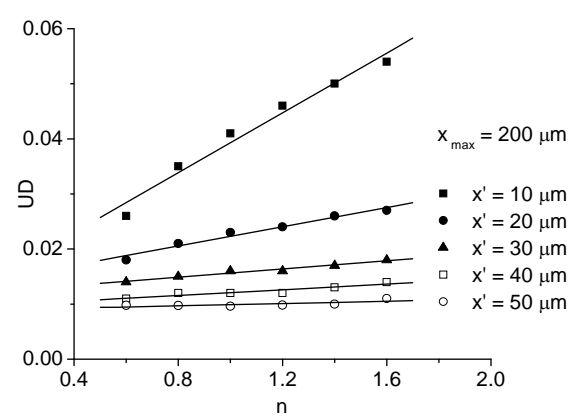

(b)

Fig. 1 - The variation of the uniformity degree with uniformity index, $U D=a+b n$

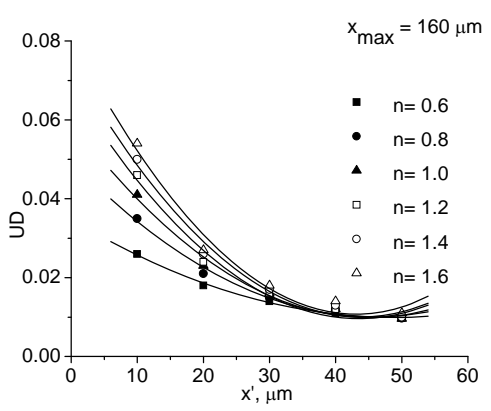

(a)

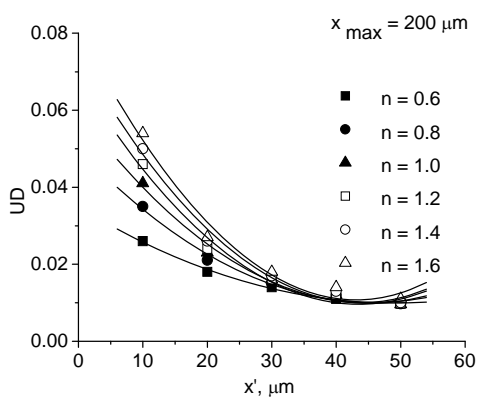

(b)

Fig. 2 - The variation of the uniformity degree with characteristic diameter, $U D=a+b x^{\prime}+c\left(x^{\prime}\right)^{2}$

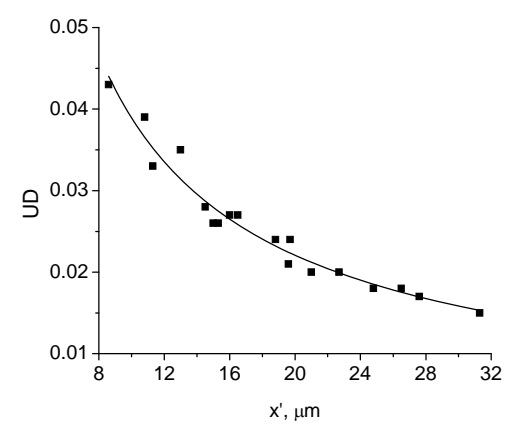

Fig. 3 - The variation of the uniformity degree with characteristic diameter, $U D=a \cdot\left(x^{\prime}\right)^{b}$ 


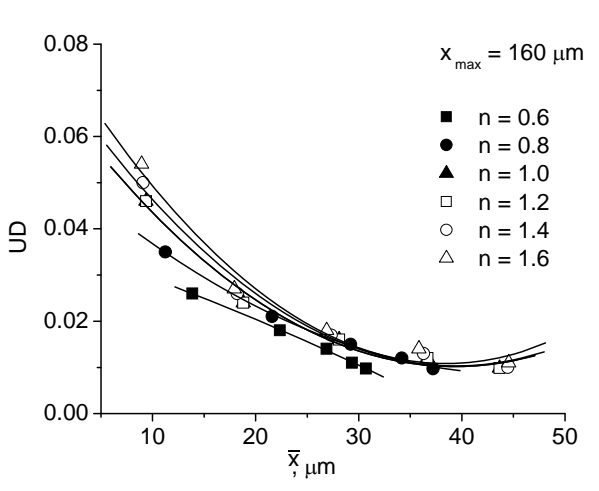

(a)

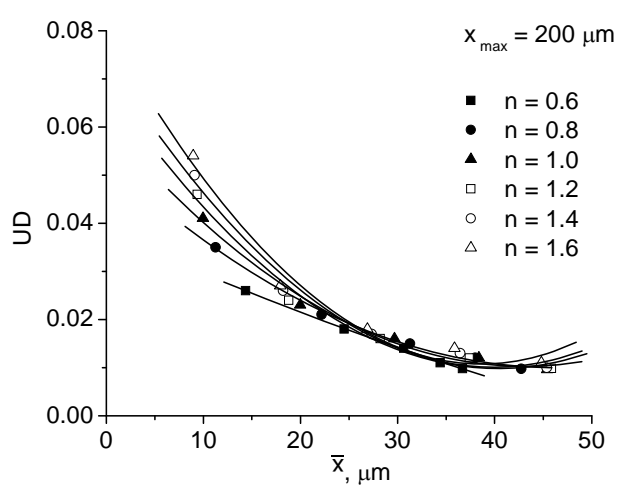

(b)

Fig. 4 - The variation of the uniformity degree with average diameter, $U D=a+b \bar{x}+c(x)^{2}$

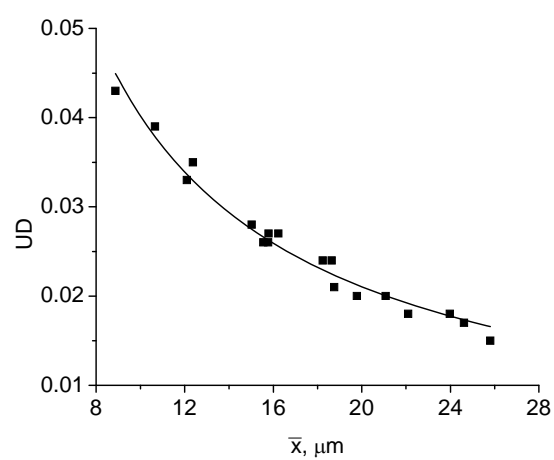

Fig. 5 - The variation of the uniformity degree with average diameter, $U D=a \cdot(\bar{x})^{b}$

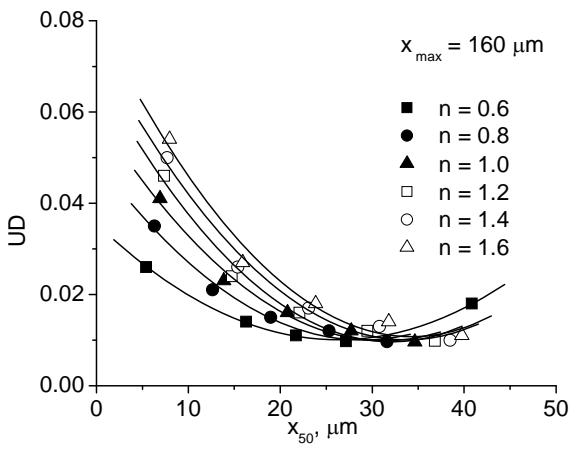

(a)

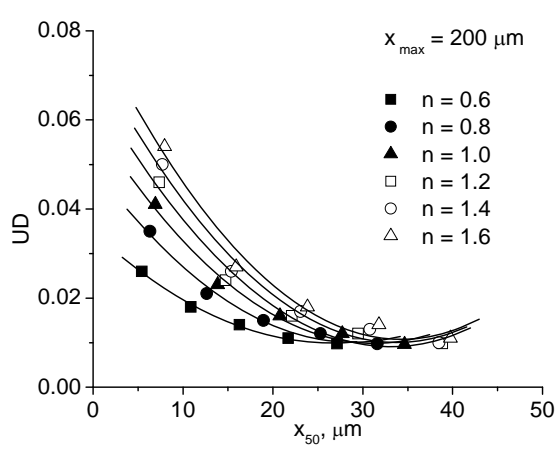

(b)

Fig. 6 - The variation of the uniformity degree with diameter, $x_{50}$, $U D=a+b x_{50}+c\left(x_{50}\right)^{2}$

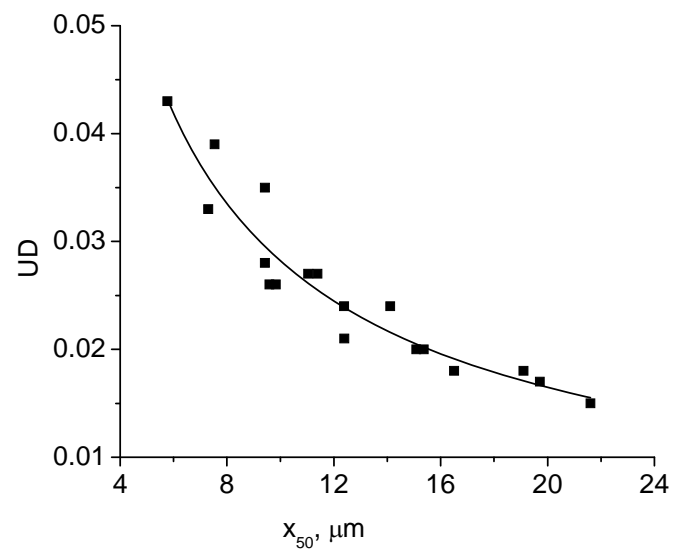

Fig. 7 - The variation of the uniformity degree with $\mathrm{x}_{50}$ diameter, $U D=a\left(x_{50}\right)^{b}$ 


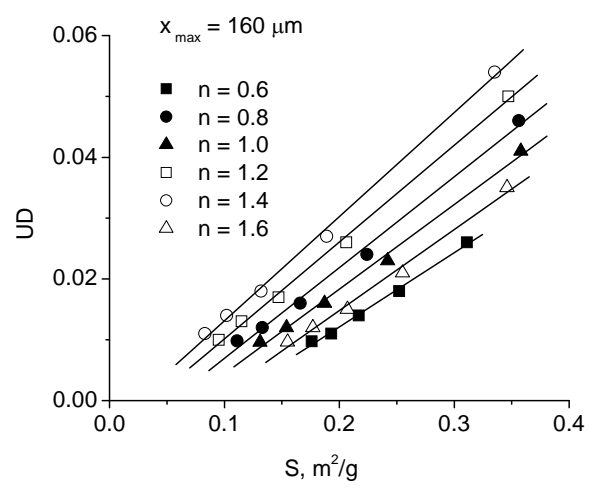

(a)

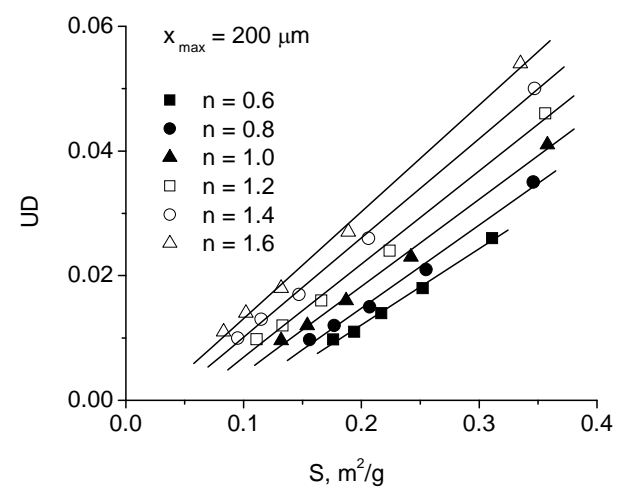

(b)

Fig. 8 - The variation of the uniformity degree cu specific surface, $U D=a+b S+c S^{2}$

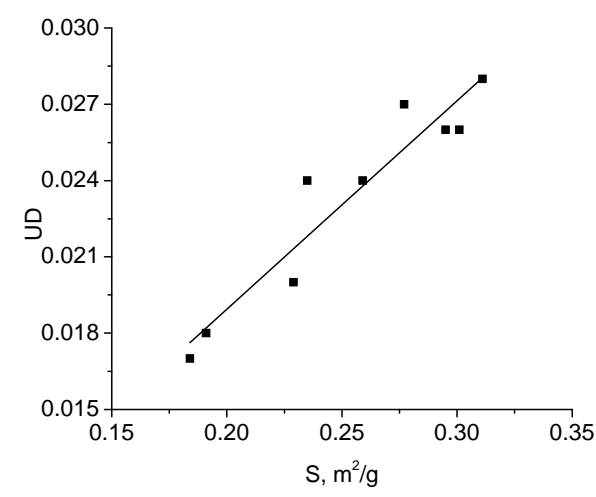

Fig. 9 - The variation of the uniformity degree cu specific surface, $U D=a+b S$

In table 4 the $\mathrm{a}, \mathrm{b}$ and $\mathrm{c}$ coefficients are presented for the equations with which the items in figures 1 - 9 were phytate points together with the values of the correlation coefficient $(\mathrm{R})$.

Table 4

Coefficient values ("a", "b", "c") of the regression equation describing the layout of points in figures figures 1 - 9 together with the values of the correlation coefficient (R)

\begin{tabular}{|c|c|c|c|c|c|c|c|c|}
\hline No. & $\mathbf{n}$ & $\mathbf{x}^{\prime}, \mu \mathbf{m}$ & $\mathbf{x}_{\max }, \mu \mathrm{m}$ & $\mathbf{a}$ & b & C & $\mathbf{R}$ & Figure no. \\
\hline \multirow{10}{*}{1} & & 10 & \multirow{5}{*}{160} & 0.012 & 0.027 & & 0.986 & \multirow{5}{*}{ Fig. 1a } \\
\hline & & 20 & & 0.013 & 0.008 & & 0.984 & \\
\hline & & 30 & & 0.011 & 0.003 & & 0.982 & \\
\hline & & 40 & & 0.009 & 0.002 & & 0.931 & \\
\hline & & 50 & & 0.008 & 0.001 & & 0.951 & \\
\hline & & 10 & \multirow{5}{*}{200} & 0.012 & 0.027 & & 0.986 & \multirow{5}{*}{ Fig. 1b } \\
\hline & & 20 & & 0.013 & 0.008 & & 0.984 & \\
\hline & & 30 & & 0.011 & 0.003 & & 0.982 & \\
\hline & & 40 & & 0.009 & 0.002 & & 0.931 & \\
\hline & & 50 & & 0.008 & 0.001 & & 0.951 & \\
\hline \multirow{12}{*}{2} & 0.6 & & \multirow{6}{*}{160} & 0.101 & 8.161 & 0.997 & 0.998 & \multirow{6}{*}{ Fig. $2 \mathrm{a}$} \\
\hline & 0.8 & & & 0.089 & 7.453 & 0.996 & 0.986 & \\
\hline & 1.0 & & & 0.069 & 7.114 & 0.997 & 0.985 & \\
\hline & 1.2 & & & 0.054 & 6.655 & 0.997 & 0.981 & \\
\hline & 1.4 & & & 0.036 & 6.269 & 0.998 & 0.980 & \\
\hline & 1.6 & & & 0.023 & 5.825 & 0.998 & 0.975 & \\
\hline & 0.6 & & \multirow{6}{*}{200} & 0.101 & 8.141 & 0.997 & 0.995 & \multirow{6}{*}{ Fig. 2b } \\
\hline & 0.8 & & & 0.090 & 7.445 & 0.996 & 0.986 & \\
\hline & 1.0 & & & 0.069 & 7.133 & 0.997 & 0.985 & \\
\hline & 1.2 & & & 0.054 & 6.655 & 0.997 & 0.978 & \\
\hline & 1.4 & & & 0.036 & 6.269 & 0.998 & 0.980 & \\
\hline & 1.6 & & & 0.023 & 5.825 & 0.998 & 0.975 & \\
\hline
\end{tabular}




\begin{tabular}{|c|c|c|c|c|c|c|c|c|}
\hline No. & $\mathbf{n}$ & $\mathbf{x}^{\prime}, \mu \mathbf{m}$ & $\mathbf{x}_{\max }, \mu \mathrm{m}$ & $\mathbf{a}$ & b & C & $\mathbf{R}$ & Figure no. \\
\hline 3 & & & & 0.046 & -0.001 & & 0.852 & Fig. 3 \\
\hline \multirow{12}{*}{4} & & 0.6 & \multirow{6}{*}{160} & 0.037 & $-7.303 \cdot 10^{-4}$ & $-5.241 \cdot 10^{-6}$ & 0.999 & \multirow{6}{*}{ Fig. $4 \mathrm{a}$} \\
\hline & & 0.8 & & 0.054 & -0.002 & $2.157 \cdot 10^{-5}$ & 0.997 & \\
\hline & & 1.0 & & 0.070 & -0.003 & $3.893 \cdot 10^{-5}$ & 0.986 & \\
\hline & & 1.2 & & 0.070 & -0.003 & $3.893 \cdot 10^{-5}$ & 0.986 & \\
\hline & & 1.4 & & 0.075 & -0.003 & $4.176 \cdot 10^{-5}$ & 0.982 & \\
\hline & & 1.6 & & 0.081 & -0.003 & $4.750 \cdot 10^{-5}$ & 0.975 & \\
\hline & & 0.6 & \multirow{6}{*}{200} & 0.038 & $-9.204 \cdot 10^{-4}$ & $3.772 \cdot 10^{-6}$ & 0.999 & \multirow{6}{*}{ FIg. 4b } \\
\hline & & 0.8 & & 0.053 & -0.001 & $1.999 \cdot 10^{-5}$ & 0.996 & \\
\hline & & 1.0 & & 0.060 & -0.002 & $2.727 \cdot 10^{-5}$ & 0.989 & \\
\hline & & 1.2 & & 0.069 & -0.002 & $3.643 \cdot 10^{-5}$ & 0.983 & \\
\hline & & 1.4 & & 0.074 & -0.003 & $4.061 \cdot 10^{-5}$ & 0.981 & \\
\hline & & 1.6 & & 0.080 & -0.003 & $4.707 \cdot 10^{-5}$ & 0.975 & \\
\hline$\overline{5}$ & & & & 0.052 & -0.001 & & 0.925 & Fig. 5 \\
\hline \multirow{12}{*}{6} & & 0.6 & \multirow{6}{*}{160} & 0.035 & -0.001 & $3.686 \cdot 10^{-5}$ & 0.998 & \multirow{6}{*}{ Fig. 6a } \\
\hline & & 0.8 & & 0.049 & -0.002 & $4.700 \cdot 10^{-5}$ & 0.986 & \\
\hline & & 1.0 & & 0.059 & -0.003 & $4.083 \cdot 10^{-5}$ & 0.985 & \\
\hline & & 1.2 & & 0.068 & -0.003 & $5.746 \cdot 10^{-5}$ & 0.981 & \\
\hline & & 1.4 & & 0.074 & -0.003 & $5.668 \cdot 10^{-5}$ & 0.980 & \\
\hline & & 1.6 & & 0.081 & -0.041 & $5.987 \cdot 10^{-5}$ & 0.975 & \\
\hline & & 0.6 & \multirow{6}{*}{200} & 0.034 & -0.001 & $3.528 \cdot 10^{-5}$ & 0.995 & \multirow{6}{*}{ Fig. 6b } \\
\hline & & 0.8 & & 0.049 & -0.002 & $4.731 \cdot 10^{-5}$ & 0.986 & \\
\hline & & 1.0 & & 0.059 & -0.003 & $5.088 \cdot 10^{-5}$ & 0.985 & \\
\hline & & 1.2 & & 0.067 & -0.003 & $5.324 \cdot 10^{-5}$ & 0.978 & \\
\hline & & 1.4 & & 0.074 & -0.003 & $5.668 \cdot 10^{-5}$ & 0.980 & \\
\hline & & 1.6 & & 0.081 & -0.041 & $5.987 \cdot 10^{-5}$ & 0.975 & \\
\hline 7 & & & & 0.043 & -0.001 & & 0.802 & Fig. 7 \\
\hline \multirow{12}{*}{8} & & 0.6 & \multirow{6}{*}{160} & - -0.012 & 0.121 & & 0.997 & \multirow{6}{*}{ Fig. $8 \mathrm{a}$} \\
\hline & & 0.8 & & -0.011 & 0.133 & & 0.996 & \\
\hline & & 1.0 & & -0.009 & 0.139 & & 0.997 & \\
\hline & & 1.2 & & -0.008 & 0.149 & & 0.997 & \\
\hline & & 1.4 & & -0.005 & 0.159 & & 0.998 & \\
\hline & & 1.6 & & -0.003 & 0.171 & & 0.998 & \\
\hline & & 0.6 & \multirow{6}{*}{200} & -0.012 & 0.122 & & 0.997 & \multirow{6}{*}{ Fig. $8 \mathrm{~b}$} \\
\hline & & 0.8 & & -0.011 & 0.133 & & 0.996 & \\
\hline & & 1.0 & & -0.009 & 0.139 & & 0.997 & \\
\hline & & 1.2 & & -0.008 & 0.149 & & 0.997 & \\
\hline & & 1.4 & & -0.005 & 0.159 & & 0.998 & \\
\hline & & 1.6 & & -0.003 & 0.171 & & 0.998 & \\
\hline 9 & & & & -0.025 & 6.081 & & 0.867 & fig. 9 \\
\hline
\end{tabular}

\section{Discussion of results}

From figures 1 and 2 which show the variation of the uniformity degree with parameters $\mathrm{n}$ and $\mathrm{x}^{\prime}$ of the Rosin-Rammler-Sperling distribution the increase of the uniformity degree with the increase of the uniformity index is determined (fig. 1), and the decrease of the uniformity degree with the increase of the characteristic diameter respectively (fig. 2). The variation UD-n (fig. 1) shows that cement is characterized by uniformity degrees all the more so as the granulometric distribution is narrower, so the dispersion of the cement particles is smaller, while the variation UD-x' (fig. 2) presents a cement characterized by a high dispersion of the particles.

The UD-n (fig. 1) dependence shows that, for the same $\underline{x}_{\max }$, respectively the same $x^{\prime}$, the uniformity degree increases with the uniformity index of the Rosin-Rammler-Sperling distribution, leading to the narrowing of the cement granulometric distribution. It shows that the more a polygranular fine material (x 'less than) is the more uniform, so the particledispersion of this material is smaller. 
The correlations of the uniformity degree with $x^{\prime}, \bar{x}, x_{50}$ diameters (fig. 2, 4, 6) show that uniformity is smaller as the diameter values are bigger. This fact is normal if we take into account that in the same direction the number of granulometric classes with similar appearance frequencies increases, thus increasing the dispersion of cement particles. Also taking into account the increase of uniformity degree with that of the specific surface (fig. 8), it can be stated that a cement characterised by a small dispersion of the particles (small values for $x^{\prime}, \bar{x}, x_{50}$ diameters) is more uniform. In this case, the specific dependence UD-S is strong, being reproduced by the equation of a straight-line.

The results shown in figures $3,5,7,9$, realised on the basis of experimental data for 18 types of industrial Portland cements showed the same types of dependences as for the simulated Portland cements (fig. 2, 4, 6, 8). It results that the uniformity degree can represent a general incorporated statistic indicator for the granulometric uniformity evaluation of industrial Portland cements.

Similar conclusions are seen from the dependences presented in figures 3, 5, 7, 9 for 18 industrial Portland cements.

If the maximum diameter $\left(x_{\max }\right)$ is kept constant, the dependences $U D-x^{\prime}, U D-\bar{x}, U D-x_{50}$ from figures 2, 4 and 6 have the some variation for several fields of values of the declared granulometric characteristics; the same variation occurs in the case $n=$ constant. In order to realise a good phytate of the results a more simple dependence relation was searched, but with a high correlation coefficient (R); the parabolic function was chosen. From table 4 it can be seen that, in all the cases, the proposed dependences are characterised by $\mathrm{R}$ values greater than 0.97 .

At the same time, by keeping constant the value of one of the $x^{\prime}, \bar{x}, x_{50}$ diameters from the graphics presented in figures 2, 4, 6 one can observe the increase of the uniformity degree with that of the uniformity index of Rosin-Rammler-Sperling distribution. Thus, cement is characterised by a small dispersion of the appearance frequencies of granulometric classes.

The analysis of the graphics presented in figures 1 - 9 shows that the dependences between the uniformity degree and the granulometric cement characteristics are very strong; in all the cases, the correlation coefficients $(R)$ have values greater than 0.95 .

\section{Conclusions}

For the characterisation of polygranular materials in the speciality literature a series of distribution laws are presented, on the basis of which a series of indicators proper to the polygranular materials can be calculated: mean diameter, diameter $x_{50}$, specific surface, uniformity degree.

The results shown (theoretically and in practice) confirm the essential role of the statistic indicator uniformity degree for the characterization of polygranular materials by accentuating the quantitative correlations between the uniformity degree and a series of dimensional characteristics (different diameters: $x^{\prime}, \bar{x}$ and $x_{50}$, the specific surface) of practical interest for the industrial Portland cements. This is why in the cement industry the uniformity degree proves its usability to "design the best granulometric distribution" for industrial blending, with implications over the running and direction conditions of several equipment and technological operations, but also to determine some of the Portland cement properties [10, 11].

\section{Refrences}

[1] Asim, M.E. (1986), Particle size distribution of cement, Zement - Kalk - Gips, Vol. 39(6), 321-324.

[2] Allen, T. (1991), Particle size measurement, Powder Technology Series, $4^{\text {th }}$ edition, Chapman and Hall.

[3] Radu,D., Volcenov,A., Toader,A. (1996) Gradul de uniformitate al amestecurilor granulare şi pulverulente, Materiale de construcții, Vol. 26(1), 59-63. 
[4] Craiu,V. (1986), Statistică şi probabilităţi, Editura Didactică şi Pedagogică, Bucureşti.

[5] Voineagu,V., Maniu,A.I., Mitruț,V.C., Statistica 1, www.biblioteca-digitala.ase.ro/.../carte2.asp?

[6] González-Tello,P., Vicaria, J.M., González,P.A. (2008), A modified Nukiyama-Tanasawa distribution function and a Rosin-Rammler model for the particle-size-distribution analysis, Powder Technology, Vol. 186 (3), 278-281

[7] Zheney,J., Johnson,P.F., Red,J.S.( 1990), Improved Equation of the Continuous Particle Size Distribution for Dense Packing, J. Am. Ceram. Soc., Vol. 73(5), 1392-1395.

[8] Mihoc,Gh., Micu,N. (1980), Teoria probabilităților şi statistică matematică, Editura Didactică şi Pedagogică, Bucureşti.

[9] Ferraris,C.F., Hackley,V., Avilés,A.I. (2004), Measurement of Particle Size Distribution in Portland Cement Powder: Analysis of ASTM Round Robin Studies, Cement, Concrete and Aggregates, Vol. 26(2).

[10]Dodds,J., Baluais,G. (1993), Characterisation de la Taille des Particules, Laboratoire des Sciences du Genie Chimique, Nancy.

[11] Miller, S.J., The arithmetic and geometric mean inequality. www.williams.edu/go/math/sjmiller/public_html/OSUClasses/487/ArithMeanGeoMean.pdf.

[12] Tsivils,S., Tsimas,S. (1992), Estimation of the specific surface of the cement industry material according to their particle size distribution, Zement - Kalk - Gips, Vol. 45(3), 131-134.

[13] Radu,D., Ibriş (Mitu),C. (2001), Un indicator generalizat de definire a gradului de uniformitate granulometrică pentru amestecurile pulverulente, 9 - 13 september (1887-1890), $7^{\text {th }}$-Conference and Exhibition of the European Ceramic Society, Belgium.

[14] Radu,D., Ibriş (Mitu),C. (2004), Gradul de uniformitate - indicator statistic generalizat de apreciere a dispersiei unor amestecuri poligranulare, Revista Română de Materiale, Vol. 34(4),. 313 - 323.

[15] Onicescu,O. (1966), Energie informationelle, Comptes Rendues l'Academie des Sciences, Paris, Seria A, 263

[16] Ruban,A.B., Schubin,W.I. (1986), Rechnerische Grundlage für die Steuerung des Klinkerbrennes mit einer optimierten Korngrößenzusammensetzung des Brennguts, Zement - Kalk - Gips, Vol. 39(9), 518-519.

[17] Kuhlman K. (1985), Proportion size and characteristics of cement Part I: Strength portland cement, Zement Kalk-Gips, Vol. 28(4) 169-178. 